\title{
Cotas Universitárias no Brasil: Análise de uma década de produção científica
}

\author{
Fernanda Vieira Guarnieri \\ Prefeitura Municipal de Orlândia - Orlândia - SP - Brasil \\ Lucy Leal Melo-Silva \\ Universidade de São Paulo - Ribeirão Preto - SP - Brasil
}

\begin{abstract}
Resumo
Em 2012 foi aprovada a Lei de Cotas determinando que instituições federais brasileiras reservem 50\% das vagas para estudantes oriundos de escolas públicas, negros e indígenas. Este estudo, do tipo "estado da arte", visa sistematizar publicações sobre as Cotas em uma década no Brasil. Foram pesquisadas três bases de dados eletrônicas (Scopus/Elsevier, Periódicos CAPES e Google Scholar), utilizando os descritores: cotas; universidade; cotas universitárias; Brasil. Foram encontradas 109 publicações, organizadas em dois períodos:2003 a 2008 ( $\mathrm{N}=48$ ), e 2009 a 2013 (N=61).As categorias temáticas foram: "Embates teóricos e legais" (70,6\%); "Impactos das Cotas" (70,6\%); "Perspectivas" (36,7\%); "Critérios" $(17,4 \%)$ e "Comparações entre países" (14,7\%). Os resultados mostram que no primeiro período enfatizam-se as questões sobre a constitucionalidade das Cotas e no segundo os efeitos da experiência brasileira na sociedade. Ao final são propostos tópicos relevantes para a evolução da discussão sobre o tema.
\end{abstract}

Palavras-Chave: Ensino superior; ação afirmativa; inclusão social.

\section{University quotas in Brazil: analysis of a decade of scientific production}

\begin{abstract}
In 2012, the Quotas Law was approved, determining that Brazilian federal institutions reserve $50 \%$ of vacancies for students from public, black and indigenous schools. This state-of-the-art study aims to systematize publications on quotas in a decade in Brazil. Three electronic databases (Scopus / Elsevier, CAPES Journals and Google Scholar) were searched, using the descriptors: quotas; university; University quotas; Brazil. There were 109 publications, organized in two periods: 2003 to $2008(\mathrm{~N}=48)$, and 2009 to $2013(\mathrm{~N}=61)$. The thematic categories were: "theoretical and legal crash" (70.6\%); "Impacts of quotas" (70.6\%); "Perspectives" (36.7\%); "Criteria" (17.4\%) and "Comparisons between countries" (14.7\%). The results show that in the first period, the questions about the constitutionality of the Quotas are emphasized and in the second the effects of the Brazilian experience in the society. At the end, topics relevant to the evolution of the discussion about the theme are proposed.
\end{abstract}

Keywords: Higher Education; affirmative action; social inclusion.

\section{Cuotas universitarias en Brasil: análisis de una década de producción científica}

\section{Resumen}

En 2012 se aprobó la Ley de Cuotas, determinando que instituciones federales brasileñas guarden 50\% de las plazas para estudiantes provenientes de escuelas públicas, negros e indígenas. Este estudio, del tipo "estado de la arte", tiene por objetivo sistematizar publicaciones sobre las Cuotas en una década en Brasil. Se investigaron tres bases de datos electrónicas (Scopus/Elsevier, Periódicos CAPES y Google Scholar), utilizando los descriptores: cuotas; universidad; cuotas universitarias; Brasil. Se encontraron 109 publicaciones, organizadas en dos períodos: 2003 a 2008 (N=48), y 2009 a 2013 (N=61). Las categorías temáticas fueron: "Embates teóricos y legales" (el 70,6\%); "Impactos de las Cuotas" (el 70,6\%); "Perspectivas" (el 36,7\%); "Criterios" (el 17,4\%) y "Comparaciones entre países" (el 14,7\%). Los resultados apuntan que, en el primer período, se enfatizan las cuestiones sobre la constitucionalidad de las Cuotas y en el segundo los efectos de la experiencia brasileña en la sociedad. Por fin se propone tópicos relevantes para evaluación de la discusión sobre el tema.

Palabras Clave: Educación universitaria; acción afirmativa; inclusión social. 


\section{Introdução}

No Brasil a Lei das Cotas ( $\left.n^{\circ} 12.711\right)$ foi aprovada em agosto de 2012, como política pública de ação afirmativa na Educação Superior, após mais de uma década de debate e com muitas controvérsias. Essa medida legal e obrigatória determina que as Universidades, Institutos e Centros Federais reservem $50 \%$ das suas vagas para estudantes oriundos de escola pública. Dentre elas, haverá reserva de um percentual especial destinado a estudantes negros (autoidentificados como de cor "parda" ou "preta") e indígenas. Tal percentual será definido pela presença dessas populações no território da Instituição de Ensino Superior (IES), de acordo com o IBGE. As referidas entidades deverão se adequar em um prazo de quatro anos a partir da aprovação da nova lei.

O primeiro Programa de Cotas brasileiro foi implementado em 2003 pela Universidade Estadual do Rio de Janeiro (UERJ). Desde então, a quantidade de universidades que aderiram ao programa de cotas foi ascendendo rapidamente em um curto período. De 2003 a 2005, 14 universidades aderiram às Cotas, sendo que em 2006 esse número chegou a 43, e em 2010 já somavam 83 instituições de ensino superior com cotas (Guarnieri, 2008). Dessa forma, apesar de as cotas raciais suscitarem controvérsias no cenário mestiço-brasileiro e serem constantemente alvo de críticas, por que tantos Programas de Cotas foram implementados nas universidades antes mesmo de se tornarem lei federal?

Considerando os resultados promissores da política pública, é possível compreender que a aprovação da Lei Federal funcionou como indicador de "sucesso" das cotas, ainda que não haja consenso sobre a sua aceitação. Tal cenário dá indícios de que o Brasil estaria trilhando um caminho de quebra do paradigma, marcado pela desaprovação do tipo de ação afirmativa "racializadora" que desde o início foi questionada. A fim de contribuir para a compreensão sobre esse complexo processo que levou ao desfecho da aprovação da referida Lei, são descritos, a seguir, fatos que marcaram tal desencadeamento no cenário brasileiro.

O ano de 2001 foi um marco inicial em função de um importante evento em Durban que manchou internacionalmente a "boa reputação" da nação brasileira, que era até então tida como referência no manejo harmonioso das relações étnico-raciais em seu território. Trata-se da III Conferência contra Xenofobia e Discriminação sediada em Durban na África do Sul. Esse evento contou com a participação de representantes do movimento negro brasileiro que denunciaram ao mundo os efeitos perniciosos do "racismo à brasileira", que apesar de aparentemente silenciosos estariam bastante vivos nos discursos naturalizados os quais sustentariam a condição de marginalidade e desigualdade de oportunidades entre brancos e negros desde os tempos da escravidão.

A partir desse evento, o Brasil como nação assumiu formalmente o compromisso de combater o racismo e de desenvolver ações que visassem à reparação dos danos históricos nos dias atuais. É nesse contexto que as "ações afirmativas" adquirem relevância, visto se tratar de uma alternativa que ao invés de punir o comportamento racista, enfrenta-o e promove a valorização da identidade de grupos étnico-raciais em desvantagem socioeconômica. As Cotas Universitárias surgem como um tipo de "ação afirmativa" que visaria à valorização da identidade de grupos étnicos (negros e indígenas) e sociais, além da inserção desses grupos na sociedade.

No Brasil, a UERJ foi precursora desse processo, implementando em 2003 o primeiro Programa de Cotas brasileiro. A partir daí inaugura-se no país um período de grandes especulações acerca das consequências desses programas, ao mesmo tempo em que também outras universidades foram incorporando o sistema de cotas ao processo seletivo vigente.

Assim, diversos fóruns de discussão foram formados e se tornaram verdadeiros ringues compostos por diferentes segmentos e atores sociais (acadêmicos, filósofos, militantes de movimentos sociais, representantes da sociedade civil, entre outros grupos) em torno do embate dicotômico entre os que defendiam as cotas como iniciativa de valorização e inclusão étnico-racial e os que as condenavam como prática discriminatória e inconstitucional. Alastrou-se pelo país o mal-estar gerado pelos possíveis impactos destrutivos de uma política "racializadora" em um país miscigenado como o Brasil. Os atritos ideológicos foram sendo cada vez mais exaltados em função das expectativas "devastadoras" das cotas para a sociedade e para a qualidade do Ensino Superior na opinião dos grupos contrários a essa política pública.

Em 2010 um importante acontecimento deu novo fôlego às discussões sobre o tema das cotas: a Arguição de Descumprimento de Preceito Fundamental (ADPF) ${ }^{1} n^{0} 186$, que tratou de questionamentos acerca da constitucionalidade do sistema de cotas raciais na UnB, prevendo a reserva de $20 \%$ das vagas para estudantes negros. Seu foco principal foi a contestação do critério racial no processo seletivo, sendo desse modo contrária à implementação de um Estado racializado (Schulze, 2012). Apesar de ter sido convocado para tratar de um sistema de cotas em uma Universidade específica, tal evento teve repercussão nacional: “... o julgamento da ADPF $n^{\circ} 186$ anuncia-se como divisor de águas para as políticas de igualdade racial no país" (IPEA, 2011, p.295).

Houve grande repercussão das entidades e demais órgãos envolvidos que gostariam de expor outros pontos de vista ao Supremo Tribunal Federal (STF) e este, ao invés de aderir às críticas e inviabilizar o prosseguimento desse sistema, optou por ampliar a participação na discussão e convocou diferentes setores da sociedade para uma audiência pública. Tal recurso foi utilizado excepcionalmente, visto se tratar de um tema de ampla repercussão social. Ao final foram ouvidos acadêmicos, parlamentares, representantes de movimentos sociais e de órgãos governamentais. A audiência foi organizada em três etapas: (a) exposição de instituições governamentais responsáveis pelas políticas de educação, pesquisa e igualdade racial; (b) espaço para apresentação de pareceres favoráveis e desfavoráveis às cotas raciais enquanto "ação afirmativa"; e (c) apresentação de experiências das universidades públicas com as cotas. 
As principais críticas ao sistema de cotas raciais foram: inexistência biológica das raças; caráter ilegítimo das ações de "reparação" aos danos causados pela escravidão em tempo presente; risco de acirrar o racismo no Brasil; possibilidade de manipulação estatística da categoria "parda"; inviabilidade de identificação racial em um país mestiço; a questão da pobreza como determinante da exclusão social.

Os argumentos favoráveis concentraram-se na discussão sobre a constitucionalidade das cotas e relevância para o país. A intervenção do Estado foi colocada como fundamental diante dos quadros de desigualdade raciais remanescentes de fenômenos sociais que precisam ser enfrentados; destacando-se que as "ações afirmativas" atuariam como alternativa para a busca de igualdade através da promoção de condições equânimes entre brancos e negros. Ressaltou-se também que "seu impacto seria muito mais profundo, permitindo o avanço do pluralismo nas diversas instituições nacionais" (IPEA, 2011, p.291).

Ao analisar diferentes modalidades de "ações afirmativas" raciais em universidades brasileiras desenvolvidas até 2012, Daflon (2013) conclui que há no país grande heterogeneidade de critérios, com implicações negativas acerca da aceitação dos critérios raciais pela população em geral. A desigualdade social tende a ser mais aceita como critérios de inclusão dos Programas. Outro aspecto colocado pelo referido autor revela diferentes modos de implementar as cotas no país, assumindo diferentes identificações de público beneficiário (egressos de escola pública; negros; indígenas; portadores de deficiência; cotas regionalizadas; nativos do estado; alunos de baixa renda; filho de policial e bombeiro; Quilombolas; mulheres) e critérios de inserção (cotas; cotas e acréscimo de vagas; bônus; cotas e bônus; acréscimo de vagas; bônus e acréscimo de vagas).

Daflon (2013) refere tal diversidade como resultado de diferentes leituras no país acerca das desigualdades sociais e raciais além dos objetivos atribuídos às "ações afirmativas". Há uma aceitação maior em relação a critérios sociais do que raciais para a promoção de igualdade no país. O estudo ressalta que a Lei de Cotas teria como finalidade amenizar tais disparidades. "De qualquer forma, sob essa nova realidade de estabilidade e relativa homogeneidade legal, os interesses de pesquisa começam a se voltar para os critérios de avaliação e desempenho das políticas, o que é em si um desenvolvimento muito positivo" (Daflon, 2013, p.23). De acordo com o autor, foi identificada a tendência geral nos programas analisados de aproximar a configuração dos alunos de ensino superior da realidade sociodemográfica do país.

Diante desse contexto complexo, de que modo a produção do conhecimento acompanhou essa trajetória de consolidação da política pública que reserva cotas universitárias no Brasil? Quais as repercussões dessas experiências sob a perspectiva de investigadores? A produção do conhecimento ao longo desse período sinaliza tendências no modo de abordar o tema das cotas brasileiras? Qual o estado da arte nesse domínio do conhecimento?

Desse modo, o presente estudo visa, a partir da revisão da literatura, descrever e analisar a produção do conhecimento sobre as cotas universitárias em uma década de existência no Brasil. Nessa revisão da literatura são evidenciados os marcos históricos e os rumos das discussões publicadas no início da implementação das cotas e nos 10 anos subsequentes, de modo a comparar dois períodos de acordo com o ano de publicação.

\section{Método}

Este estudo é do tipo "estado da arte", que consiste no mapeamento e na análise da produção científica de diversas áreas do saber, na tentativa de apreender o que vem sendo destacado em diferentes épocas (Ferreira, 2002). Estudos desse tipo possuem caráter documental e visam analisar as ideias centrais contidas nas publicações, uma vez que os mesmos são considerados fontes estáveis de informação que contribuem para elaboração de panoramas relevantes sobre determinado tema (Gil, 2002).

Para levantamento dos dados foram realizadas buscas em três bases de dados virtuais: Scopus/Elsevier, Periódicos Capes e Google Scholar. As três bases consultadas contam com amplo acervo e permitem a realização de buscas em diferentes áreas do saber e variadas fontes (artigos, teses, dissertações, resenhas, resumos, entre outras) de âmbito nacional e internacional. Elas disponibilizam conteúdo de publicações acadêmicas, repositórios online, bibliotecas e portais universitários. O acesso às bases Scopus/Elsevier e Periódicos Capes é restrito às instituições acadêmicas e aos pesquisadores filiados. Já o acesso ao Google Scholar ou Acadêmico é público e irrestrito. Por sua vez, a análise dos dados foi realizada de acordo com a Análise de Conteúdo de Bardin (1977) que consiste na sistematização da análise de conteúdo em quatro etapas. A primeira é a "pré-análise", que corresponde à leitura flutuante que possibilita a definição dos eixos temáticos dos trabalhos encontrados. A segunda consiste na "exploração do material" ou a gestão sistemática das definições da etapa anterior. Já as duas últimas etapas, "tratamento dos resultados obtidos" e "interpretação" compõem-se através das inferências do autor que relaciona seu parecer técnico em todo o processo de análise dos resultados obtidos.

\section{Procedimentos de coleta e análise dos dados}

Foram realizadas buscas utilizando-se os descritores em inglês e português: "quotas"|"cotas", "university"|"universidade", "Brazil”| "Brasil", no período compreendido entre os anos 2003 e 2013, marcando uma década de existência das Cotas brasileiras, acrescentando-se como filtro a expressão exata "cotas universitárias"/ "university quotas" afim de centralizar o objeto de estudo.

$\mathrm{Na}$ etapa inicial da Análise, foi realizada leitura flutuante do material encontrado a fim de adequar a busca aos 
objetivos deste estudo. Desse modo, foram eliminadas: as publicações repetidas nas bases de dados, aquelas com dados incompletos nos resumos e arquivos indisponíveis para consulta. Na segunda leitura do material foram eliminados aqueles estudos que apesar de abordarem questões étnicas e raciais, genéticas e biológicas, não faziam alusões às Cotas no Ensino Superior brasileiro. Produções sobre reservas de vagas para outros grupos minoritários (mulheres, portadores de deficiência, entre outros) também foram descartados por não se enquadrarem em nenhum dos grupos minoritários preconizados pela Lei de Cotas ( $n^{\circ} 12.711 / 12$ ). Nessa etapa do percurso metodológico chegou-se ao total de 109 produções, que constituíram o corpus de análise para este estudo.

Na etapa de "exploração do material", após a releitura flutuante dos resumos, foram identificados os conteúdos e a partir deles definidas 13 subcategorias ou componentes, que foram reorganizadas e deram origem a cinco categorias temáticas mais amplas. Com essa organização foi feita a análise de dados. A seguir são detalhadas como as subcategorias foram organizadas dando origem às categorias que possibilitaram a análise do conteúdo nos dois períodos, dois ciclos de cinco anos em uma década.

1. Embates teóricos e legais: Categoria composta pelo agrupamento de subcategorias que se relacionam às questões teóricas e filosóficas, à ênfase ao contexto histórico em que os programas de Cotas foram criados e à avaliação da implementação de ações como as Cotas em termos legais. Nesta categoria estão estudos com ênfase na teorização do processo de inserção das cotas no Brasil, que ressaltam a trajetória histórica da consolidação de "ações afirmativas" no país, associando diversas frentes teóricas (Sociologia, Antropologia, História, Direito, entre outras).

2. Impactos das Cotas Universitárias. Categoria temática que reuniu estudos que enfatizam a investigação sobre os programas de Cotas em funcionamento no contexto brasileiro, seus efeitos e desafios para a sociedade brasileira. As subcategorias que the deram origem foram aquelas com foco sobre os impactos, reflexões sobre os efeitos da inclusão e da promoção de diversidade, exposição de experiências brasileiras com as Cotas no Ensino Superior, estudos envolvendo repercussões sobre as populações indígenas e sugestões sobre outros formatos de ações afirmativas.

3. Critérios de inclusão. Categoria temática que reúne produções com ênfase na identificação, avaliação e construção de diferentes critérios utilizados nos programas de cotas, tanto os de definição étnico-raciais, quanto outros, como por exemplo: critério social, bônus por desempenho, entre outros.

4. Perspectivas diversas sobre as Cotas. Estudos que trazem pontos de vista de diferentes grupos e agentes sociais sobre as cotas. Fazem parte deste grupo as subcategorias: diferentes perspectivas, e questionamentos pró ou contra cotas. Foram incluídos nesta categoria os estudos que exploram tanto perspectivas sobre a possibilidade da implementação dos programas em médio e longo prazo, quanto perspectivas de atores sociais envolvidos diretamente com as cotas.

5. Comparação entre Países. Reuniu estudos que visam comparar modelos de cotas em universidades de outros países com o do Brasil.

$\mathrm{Na}$ etapa de análise e tratamento dos resultados as publicações foram organizadas também em dois períodos, de acordo com o ano de publicação. O primeiro período (P1) contém publicações realizadas no início da implementação de programas de Cotas Universitárias no contexto brasileiro, entre 2003 a 2008, e o segundo período (P2) contém as publicações de 2009 a 2013, ciclo entendido como de maior consolidação da experiência brasileira, com a presença de cotas e de cotistas nas universidades, com o processo em andamento em diferentes programas universitários, englobando o ano da aprovação da Lei das Cotas ( $\left.n^{\circ} 12.711 / 12\right)$. É importante ressaltar também que, na maioria das publicações, foi identificada mais de uma categoria temática, dado levado em consideração na análise dos resultados. Assim, na Tabela 1 o número total de respostas (181) é maior do que o de produções analisadas.

Os resultados, a seguir, são apresentados em duas subseções. A primeira sobre a Análise da Produção e a Comparação entre os dois períodos, ou seja, os resultados propriamente ditos. A segunda subseção destaca alguns tópicos relevantes para serem inseridos em pautas sobre a evolução dos programas de Cotas Universitárias.

\section{Resultados e Discussão}

\section{Análise da Produção e Comparação entre os dois períodos (P1 e P2)}

Foram analisadas 109 produções, sendo que o $1^{\circ}$ período contém 48 publicações (43\% do total de publicações) e o $2^{\circ}$ período com 61 (56\%). Sobre as fontes das produções os resultados mostram que os estudos foram publicados tanto em periódicos internacionais quanto nacionais sinalizando o interesse e a repercussão internacional sobre a temática das Cotas nas Universidades brasileiras. Os 30 periódicos internacionais nos quais os artigos foram publicados são: Advances in Education in Diverse Communities: Research, Policy and Praxis; American Journal of Sociology; American Sociological Review; Antípoda - Revista de Antropología y Arqueología; Du Bois Review: Social Science Research on Race; Growing Gaps: Educational Inequality around the World; Economics of Education Review; Higher Education; Human Heredity; International Encyclopedia of Education; International Journal of Educational Development; Journal of Human Resources; 
Journal of Latin American Studies; Journal of Latin American Studies; Katálysis; Latin American and Caribbean Ethnic Studies; Latin American Perspectives Latin American Research Review; Lusotopie; New York University Review of Law and Social Change; Nuevo mundo: mundos nuevos; Revista Electrónica Teoría de la Educación, Educación y Cultura en la Sociedad de la Información; Springer Netherlands; The Economist; The National Black Law Journal; The Overseas Development Institute (ODI); University of Miami International and Comparative Law Review; Vibrant - Virtual Brazilian Anthropology; Widening participation and lifelong learning; World Association of Public Opinion Research.

Cumpre destacar a particularidade do periódico "Vibrant" que conta com uma equipe editorial composta por membros de renomadas universidades brasileiras no campo da pesquisa e é considerada fonte internacional de informação e tem como finalidade divulgar estudos antropológicos brasileiros para o mundo, disponibilizando-os em inglês, espanhol e francês. Quanto às fontes nacionais, os 31 periódicos encontrados foram: Cadernos de Pesquisa; Currículo sem Fronteiras; Direitos Culturais; Dados; Educação e Pesquisa; Educação e Sociedade; Educação Temática Digital (ETD); Ensaio; Ensaio: Avaliação de Políticas Públicas na Educação; Estudos Avançados; Estudos Econômicos; Estudos e Pesquisas em Psicologia; Fractal: Revista de Psicologia; Novos Estudos Jurídicos; Novos EstudosCEBRAP; Pensar: Revista de Ciências Jurídicas; Psicologia \& Sociedade; Revista Argumenta, Revista ABPN; Revista
Brasileira de Economia; Revista Brasileira de Educação; Revista Brasileira de Estudos de População; Revista Direito;Revista da Faculdade de Direito da UFPR; Revista de Ciências da Administração; Revista de Ciências Humanas; Revista Estudos Feministas; Sociedade e Cultura; Revista Libero; Revista Sínteses; Virtuajus.

Em relação à produtividade, o ano de 2010 destacou-se com 20 publicações, coincidindo com o ano em que ocorreu o ADPF que reascendeu o debate sobre o tema, como mostra a Figura 1. Os anos 2008 e 2012 também reúnem números expressivos de publicações, ambos com 17 produções. É importante contextualizar alguns fatos históricos relativos a esses dois anos. Em 2008 foram graduadas as primeiras turmas de universitários cotistas e, em 2012, foi aprovada a Lei de Cotas.

Em relação à análise das categorias temáticas, as mais representativas, em termos gerais, foram: "Embates Teóricos e Legais" e "Impacto das Cotas", ambas as categorias presentes em 77 (70,6\%) das produções cada, conforme a Tabela 1. A categoria "Perspectivas sobre as Cotas" esteve presente em 40 (36,7\%); seguidas por "Critérios de Inclusão" com 19(17,4\%) e "Comparação entre Países"com 16 (14,7\%).Pode-se identificar a predominância das seguintes categorias: Embates Teóricos e Legais, Impactos das Cotas e Perspectivas. As três categorias articuladas dão indícios sobre as preocupações dos autores em contextualizar as cotas, embasando teoricamente o desenrolar dessas políticas em um momento histórico específico, levando em consideração como diferentes grupos sociais se posicionam

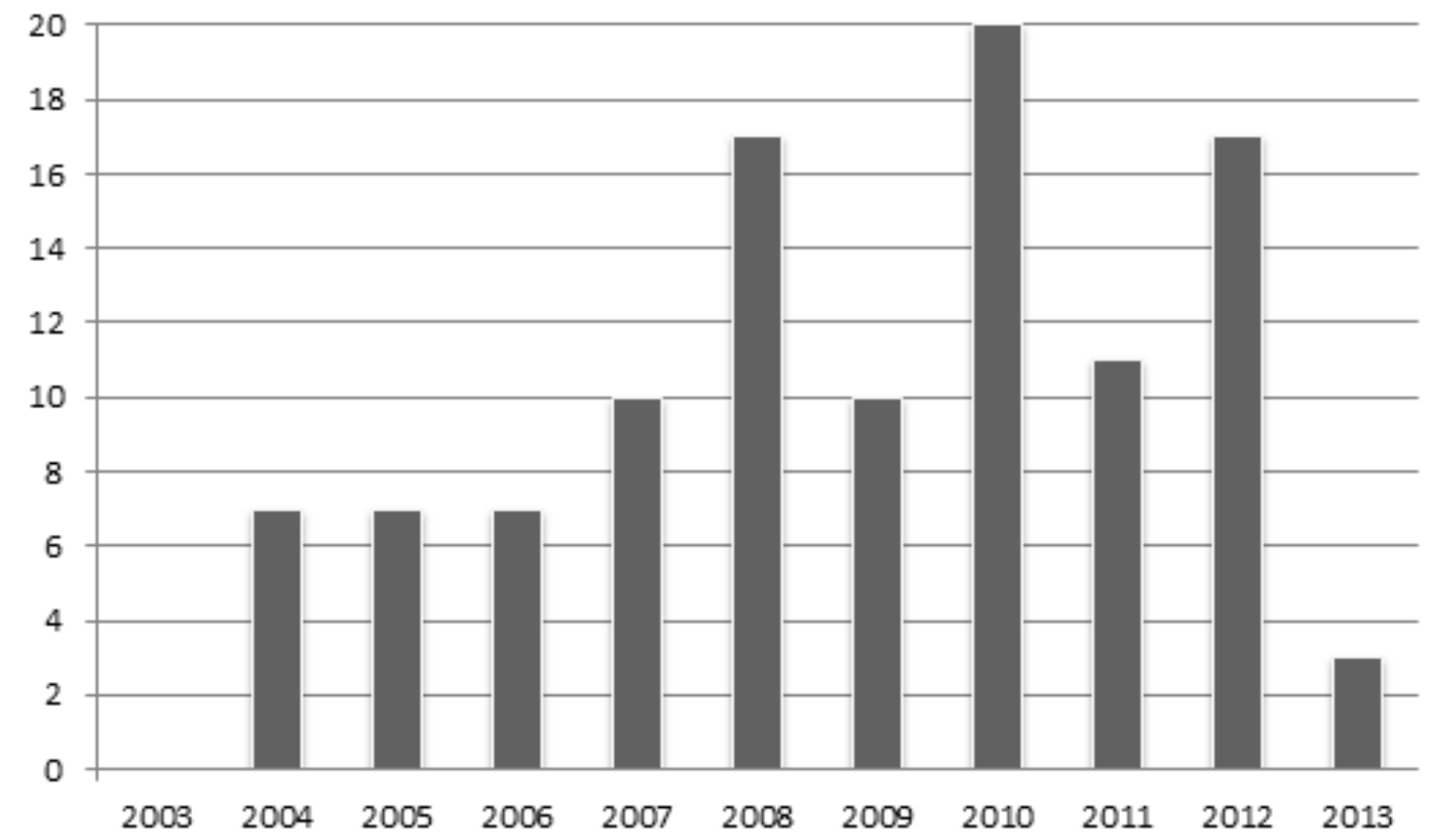

Figura 1. Distribuição da produção sobre Cotas Universitárias no Brasil por ano de publicação 
Tabela 1. Distribuição dos eixos temáticos em função da representatividade em termos numéricos e percentuais nos dois períodos considerados, P1 e P2.

\begin{tabular}{|c|c|c|c|c|c|c|c|}
\hline & \multirow{2}{*}{ Categorias } & \multicolumn{2}{|c|}{ Total } & \multicolumn{2}{|c|}{ P1 } & \multicolumn{2}{|c|}{ P2 } \\
\hline & & $\mathrm{N}$ & $\%$ & $\mathrm{~N}$ & $\%$ & $\mathrm{~N}$ & $\%$ \\
\hline 1 & $\begin{array}{l}\text { Impactos das Cotas } \\
\text { universitárias }\end{array}$ & 58 & 32 & 22 & 12 & 36 & 20 \\
\hline 2 & Embates Teóricos & 57 & 31 & 32 & 17,4 & 25 & 13,6 \\
\hline 3 & Critérios de Inclusão & 32 & 18 & 15 & 8,4 & 17 & 9,6 \\
\hline 4 & $\begin{array}{c}\text { Perspectivas sobre as Cotas } \\
\text { Universitárias }\end{array}$ & 24 & 13 & 13 & 7 & 11 & 6 \\
\hline 5 & Comparação entre países & 10 & 6 & 5 & 5 & 5 & 5 \\
\hline
\end{tabular}

em relação às Cotas já implementadas ou apenas quanto à possibilidade de que sejam efetivadas.

Quando as categorias temáticas são analisadas por período, são observadas especificidades. No primeiro período, P1( $\mathrm{N}=48)$, destacam-se a categorias: "Embates teóricos e legais", presente em $81,2 \%(n=39)$ das publicações desse período; "Impactos das Cotas", em $58,3 \%(n=28)$ e "Perspectivas" em $50 \%(n=24)$. Em relação às publicações do segundo período, $\mathrm{P} 2(\mathrm{~N}=61)$, as categorias mais representativas foram respectivamente: "Impactos das Cotas Universitárias", presente em 80,3\% ( $n=49)$; "Embates teóricos e legais" em 62,3\% ( $n=38) ;$ e "Perspectivas" em 26,2\% ( $n=16)$ das publicações do P2.

Foi possível identificar diferenças no tipo de abordagem realizada nos dois períodos ( $\mathrm{P} 1$ e $\mathrm{P} 2)$. Em relação à categoria "Impactos das Cotas" em P1, os estudos focalizam hipóteses e expectativas de sucesso ou fracasso, associados à ideia de cotas. Já em P2 a ênfase desta categoria é dada aos resultados obtidos por meio da concretização dos programas, trazem assim contribuições para atualização do debate, apresentando dados de pesquisas com levantamento de aspectos positivos e/ou negativos, avaliados a partir da prática e não apenas de concepções teóricas e/ ou ideológicas para justificaras expectativas dos próprios autores.

Sobre a categoria "Perspectivas sobre Cotas Universitárias", no primeiro período a temática é abordada em $58,3 \%$ das publicações, o que pode ser inferido como interesse dos autores na exploração de opiniões e expectativas de diferentes grupos sociais sobre as cotas ainda em discussão. Assim, como na categoria "Impactos das cotas" o foco das publicações em P1 recai sobre o levantamento de perspectivas hipotéticas, ou seja, as cotas como possibilidade. Já no segundo período, os estudos são orientados pelo levantamento de pontos de vista considerando os programas de cotas já em funcionamento nas universidades.

Verifica-se, portanto, que há diferenças no tipo de abordagem dada ao tema de acordo com o período em que foi publicado. No primeiro período os questionamentos que impulsionaram a produção do conhecimento visaram responder ao debates obre a implementação de uma política racial em uma cultura miscigenada. Daí a busca por argumentação ora de defesa, ora de ataque a esta política de ação afirmativa. No segundo período, observa-se que a dicotomia entre posicionamentos favoráveis ou contrários às cotas dá lugar a outros questionamentos ligados à inserção adequada dos grupos sociais em desvantagem, à promoção e à aceitação da diversidade no contexto universitário. Importante ressaltar que o contexto do segundo período é marcado pela aceitação da constitucionalidade das cotas. Destaca-se nesse período a exploração de modelos já implementados e em funcionamento, lançando-se em direção às possibilidades complementares de ações afirmativas.

Em síntese, nas publicações de 2003 a 2008 foram verificadas algumas tendências: (a) a marca da argumentação dicotômica de defesa ou ataque às Cotas Universitárias em relação a sua constitucionalidade, com a definição de critérios (Pena \& Bortoline, 2004; Pimentel \& Santos Pereira, 2004; Durham, 2005; Santos, 2006) e (b) levantamento de opiniões por diferentes segmentos sociais e os impactos esperados (Vasconcelos \& Silva, 2005; Guarnieri \& Melo-Silva, 2010; Menin, Shimizu, Silva, Cioldi, \& Buschini, 2008). Por sua vez, na produção do período 2009-2013, há destaque para aspectos positivos relacionados à diversidade promovida pela inclusão adequada dos grupos sociais em desvantagem, tanto em relação à educação superior quanto à sociedade como um todo. O contexto considerado é de aceitação da constitucionalidade das cotas, cujo marco se deu em 2010, com a ADPF $n^{\circ} 186$. Destaca-se também a presença significativa de estudos que analisam e acompanham a política pública brasileira e seus impactos ao longo dos anos (Andrade, 2010; Cicalo, 2012; Francis \&Tannuri-Pianto, 2012a, 2012b; Penha-Lopes, 2013; Silva \& Silva, 2012), visando à melhoria dos programas e sugerindo alternativas desenvolvidas a partir desses estudos.

Há questões que estão sendo superadas a partir da observação empírica de programas de cotas no Brasil; no entanto, há desafios que se colocam para além a discussão dicotômica sobre quem é a favor ou contra as cotas. De 
acordo com estudo realizado por Bolonha \& De Teffé (2012), as cotas representam avanço e podem exercer influências positivas no plano social e cultural brasileiro. "As cotas traduzem um planejamento de longo prazo capaz de promover justas mudanças no cenário brasileiro não apenas educacional, e sim, em sua plenitude" (Bolonha, 2012, p.140). No entanto, o autor aponta problemas ligados a falhas na comunicação entre o Estado e a sociedade civil, o que tende a minar tais efeitos. Aponta ainda como solução a padronização ou normatização das cotas, sugerindo assim apoio à Lei de Cotas, que foi aprovada no mesmo ano da publicação do referido autor.

Mesmo com a aprovação da Lei de Cotas, é necessário avançar. As cotas são uma realidade brasileira que já superaram a condição "movediça" de sua constitucionalidade. A experiência brasileira com Cotas no Ensino Superior tem se mostrado campo fértil de investigação sobre uma política de ação afirmativa em um país marcado pela desigualdade socioeconômica, e que vem evidenciando novas possibilidades de implementação da medida a partir da superação da dicotomia a favor ou contra. Dessa forma, com base nesse pressuposto, alguns eixos temáticos tendem a se enfraquecer em termos de volume de publicações. É o caso de estudos com foco sobre a avaliação da constitucionalidade da legislação e dos regimentos, pois uma vez que a as cotas foram traduzidas em lei, reduz-se a relevância desse tipo de estudo. Assim, independentemente de haver consenso sobre a aceitação das cotas, elas são hoje uma realidade garantida por lei. O interesse pelo confronto dicotômico (pró versus contra) vem diminuindo na literatura. Estudos mais recentes tendem a superar esse tipo de confronto identificando, a partir de pesquisas e investigações acerca dos envolvidos no processo, quais avanços vão de encontro à sustentabilidade dos programas e quais são as novas demandas e obstáculos a serem sobrepostos.

A seguir, são tecidas algumas considerações, a partir da análise dos dados, que foram consideradas pertinentes para serem inseridas em pautas sobre a evolução dos programas de Cotas Universitárias no Brasil.

\section{Tópicos Relevantes para a continuidade do debate}

Algumas observações são destacadas nesta subseção envolvendo três subtítulos que poderão constituir pautas contemporâneas e futuras a respeito do tema Cotas Universitárias os quais serão abordados a seguir: (a) desempenho acadêmico, ações de inclusão e permanência na universidade; (b), alternativas às cotas, e (c) atendimento às populações indígenas.

Sobre o desempenho acadêmico, ações de inclusão e permanência, destacam-se os estudos de acompanhamentos dos Programas de Cotas efetivos no Brasil realizados por Weller e Silveira (2008), Schwartzman (2009), Santos e Queiroz (2010) e Cicalo (2013). Os autores trouxeram informações que relativizam as previsões negativas acerca do desnivelamento educacional entre estudantes cotistas e não-cotistas e os impactos sobre o desempenho acadêmico precário do aluno cotista, além da provável queda de qualidade do ensino no Ensino Superior. Tais estudos apontam que o desempenho médio do aluno cotista não é significativamente inferior ao do aluno não-cotista (Cardoso, 2008), sendo citados, em alguns casos, como superior. Além disso, são fornecidos indicativos de que a taxa de evasão do estudante cotista é geralmente menor que do não-cotista. No entanto, foram feitas ressalvas acerca de outras variáveis que afetam o rendimento e a evasão dos alunos (questão financeira, dificuldades enfrentadas por estudantes trabaIhadores, transporte, moradia, entre outros obstáculos à permanência estudantil).

Assim, não apenas o vestibular deve ser afetado pelas cotas, mas todo o contexto em que é inserido o cotista. Deve haver um esforço contínuo para promover ações que integrem e acomodem bem o aluno cotista. Mayorga e Souza (2012) chamam atenção para a questão da "permanência" dos alunos cotistas reiterando a importância de buscar por meio de ações concretas nas Universidades a fim superar o teor assistencialista e unicamente econômico das mesmas. Exemplos dessas ações: aulas de reforço, bolsas de auxílio financeiro, bolsa alimentação, fornecimento de moradias; utilização do espaço universitário para promover continuamente a integração e a discussão sobre questões étnico-raciais e para a resolução de conflitos ou problemas de toda monta ligados ao tema. Tais dados, obtidos empiricamente por meio de análises e acompanhamento sucessivos de especialistas, têm trazido novos olhares sobre a discussão sobre cotas, desnaturalizando preconceitos relativos ao tema.

Sobre as alternativas às cotas, estudos mais recentes (Guimarães, 2010; Andrade, 2010; Winther \& Golgher, 2010; Golash-Boza, 2011) apontam para outras formas de se instituir a "ação afirmativa" dentro do eixo de inserção no ensino superior, explorando-se possibilidades e novos modelos de "ação afirmativa" diferentes das cotas.

Um modelo bastante citado pela literatura foi o adotado pela UNICAMP (Tessler, 2006; Guimarães, Costa, \& Kleinke, 2009). Trata-se do Programa de Ação Afirmativa e Inclusão Social da Unicamp (PAAIS), definido como "ação afirmativa sem cotas”. Funciona como sistema de bônus, sendo que os alunos egressos de escola pública recebem bônus de 30 pontos a mais na nota final da segunda fase do vestibular. Além disso, alunos egressos de escola pública que se autodeclarem pretos, negros ou indígenas recebem mais 10 pontos de bônus. Outra alternativa encontrada em 2011 pela UNICAMP foi o PROFIS, que se trata de um curso sequencial de dois anos e possibilita o ingresso na UNICAMP de estudantes das escolas públicas de Campinas. De acordo Alison (2014), "o programa... seleciona os melhores estudantes de escolas públicas da cidade de Campinas com base na nota que obtiveram no Enem".

As outras universidades estaduais do Estado de São Paulo também estão sendo influenciadas pelas repercussões das cotas no território nacional. Em 2014, a Universidade Estadual Paulista (UNESP) se tornou a primeira universidade estadual do Estado de São Paulo a implementar 
Sistema de Cotas nos moldes da Lei de Cotas ( $n^{\circ} 12.711 / 12$ ), intitulado Sistema de Reserva de Vagas para Educação Básica Pública (SRVEBP), o qual definiu a reserva de $15 \%$ do total de vagas a estudantes egressos do ensino médio público, dentre as quais $35 \%$ destinaram-se para estudantes autodenominados pretos, pardos ou indígenas. A previsão é de que haja aumento progressivo ao longo dos anos do percentual de vagas reservadas pelo SRVEBP e que em 2018 o percentual reservado para as Cotas alcance os 50\%. Considerando que os campi da UNESP estão relativamente distribuídos em diferentes regiões do Estado de São Paulo a possibilidade de ingresso de alunos da rede pública de ensino é maior, uma vez que há escolas bem avaliadas em cidades menores (Universidade Estadual Paulista, 2015).

A Universidade de São Paulo (USP), que tradicionalmente apresenta-se mais relutante com relação à implantação das Cotas, também veio se mobilizando na busca por programas alternativos que produzam resultados eficazes de inclusão social. Uma dessas medidas é o Programa de Inclusão com Mérito no Ensino Público Paulista (PIMESP), que consiste na elaboração de um bônus racial, que estabelece acréscimo de $20 \%$ na nota do vestibular a alunos da rede pública e de até $25 \%$ aos autodeclarados negros (Minto, 2013). De acordo com o PIMESP, um aluno negro ou indígena que cursou a educação básica na rede pública poderá ter um bônus de até $25 \%$ na nota. Sem o critério racial, o bônus para a escola pública será de até $20 \%$. A proposta surgiu do posicionamento de 42 unidades da USP. Ressalta-se que diferem das Cotas propriamente ditas, tratando-se de metas de inclusão, e pretendem alcançar $50 \%$ de estudantes da rede pública até 2018. Além do sistema de bônus, a USP tem investido na oferta de cursinhos pré-vestibulares e cursos de reforço, com duração de dez meses. Serão oferecidas anualmente 1.000 vagas a alunos egressos do ensino público e que prestaram o vestibular da FUVEST e não foram aprovados. No entanto, os índices de inclusão social alcançados por esses programas na USP têm sido bastante inferiores ao esperado, visto que ainda $85 \%$ dos seus matriculados são egressos do ensino privado, brancos e de níveis sociais elevados, o que repercute na urgência da criação de alternativas mais efetivas de inclusão social nesse nível de ensino.

A questão é ainda bastante controversa e divide opiniões dentro e fora do espaço da universidade. Nesse sentido, a Faculdade de Arquitetura e Urbanismo (FAU), por meio da Congregação da FAU-USP, formada por professores, alunos e funcionários, aprovou a adoção de cotas raciais para estudantes oriundos de escolas públicas com início em 2017. Desse modo, 30\% das vagas da FAU são destinadas a alunos egressos do ensino público, dentre os quais $50 \%$ são destinadas a pessoas autodeclaradas pretas, pardas ou indígenas, com seleção por meio do Sistema de Seleção Unificada (SISU) e suspender, em caráter temporário a prova de habilidades específicas exigida para ingresso nos cursos (Lourenço, 2016). Em relação aos demais cursos, serão disponibilizadas 1.489 vagas da USP para o SISU, das quais 1.159 (ou 77,8\%) vão ser destinadas apenas para estudantes da rede pública, de modo que 225 serão destinadas especificamente para estudantes autodenominados pretos, pardos e indígenas. As 340 restantes serão disputadas na modalidade de ampla concorrência (Moreno, 2015).

Para os ingressantes em geral que necessitam de apoio financeiro a USP oferece programas de apoio à permanência estudantil com a oferta de várias modalidades de bolsa, em projetos de pesquisa, de cultura e extensão, em programas de estímulo ao ensino de graduação, de educação tutorial, e auxílios diversos à moradia, à alimentação e ao transporte, entre outras iniciativas, pois se entende que para além da democratização do acesso é preciso que as políticas de permanência e desenvolvimento acadêmico sejam eficazes.

Sobre o atendimento às populações indígenas, as caladas vozes, chama atenção a escassez de estudos que abordem questões ligadas aos povos indígenas, grupo minoritário contemplado pela Lei de Cotas. Foram encontrados artigos apenas no segundo período (Garlet, Guimarães, \& Bellini, 2010; Athayde, 2010).

Cabe ressaltar que os indígenas representam o terceiro maior grupo de beneficiários das políticas de ação afirmativa no ensino superior brasileiro, sendo superado apenas pelo grupo de egressos do ensino público e os negros (Daflon, 2013). Essa aparente falta de interesse da literatura em abordar as ações voltadas ao referido segmento social pode estar relacionado à baixa representatividade dos indígenas nas universidades, visto que há baixo contingente de indígenas egressos do Ensino Médio (Santos, 2012). Outra questão que se coloca é em relação ao contexto histórico e político das mobilizações sociais, levantando-se que o movimento negro no Brasil, por ter se articulado há mais tempo - inicialmente por uma elite negra intelectual e alastrando-se com mais intensidade em outros nichos sociais - tenha fomentado mais questionamentos pertinentes ao negro, o que não tem acontecido ainda com os povos indígenas, pelo menos entre os estudos encontrados. Seria interessante a realização de estudos que pudessem investigar melhor as mobilizações dos povos indígenas e sua articulação com as políticas nacionais de reserva de cotas.

\section{Considerações Finais}

Em síntese, o presente estudo enfatizou a abordagem de diferentes estudos acerca das Cotas Universitárias no Brasil. Foram identificadas cinco categorias de análise que representam os últimos 10 anos de discussão sobre o tema. Há tendências nas abordagens em função do período de publicação, se no início dos debates ou embates ou no período próximo à aprovação da Lei.

As Cotas Universitárias já fazem parte da realidade brasileira e também se identificam como alternativa de socialização. Como medida de "ação afirmativa" com finalidade reparatória, configura-se em uma alternativa possível para promover a inserção do jovem em situação de desvantagem social e étnica nos espaços acadêmicos, enriquecendo tais espaços com a diversidade e possibilidade criativa derivadas desse processo, o que pode desdobrar-se em mudan- 
ças nas agendas de pesquisa, na definição de prioridades e na produção do conhecimento acadêmico.

Assim, esforços em resolver os desafios colocados à juventude brasileira devem ser realizados como ações preventivas de uma triste realidade vulnerável em que estão inseridos alguns dos segmentos jovens como as principais vítimas da violência e dificuldades crônicas de inserção social digna. Os jovens negros são hoje as principais vítimas da violência (Waiselfisz, 2013), o que se traduz em parte pela contradição vivenciada no Brasil nos últimos 20 anos, visto que, apesar da redução da mortalidade infantil o risco de morte aumentou drasticamente ao atingirem as faixas etárias jovens (IPEA, 2012). Tal fenômeno social é denominado "genocídio da juventude negra brasileira" (Soares, 2007), terminologia utilizada para traduzir o crescente e assombroso número de assassinatos especialmente entre jovens negros, decorrente da expansão veloz das dinâmicas criminais. Ou seja, em termos estatísticos, a carreira criminosa incide principalmente sobre os jovens negros e infelizmente os acolhe enquanto a sociedade civil por sua inabilidade e deficiência estrutural os exclui da educação qualificada em todos os níveis de ensino.

$O$ enfrentamento desses desafios deve superar qualquer tentativa isolada de ações nas questões de juventude. Urge que haja maior engajamento social não só dos órgãos envolvidos especificamente nessas questões (como o Conselho Nacional da Juventude - CONJUVE², e demais instâncias governamentais juvenis), mas que toda a sociedade utilize espaços de reivindicação e de criação de novas possibilidades para incluir, cada vez mais, essa faixa etária que representa parte expressiva da população. $O$ acesso à educação é avaliado por Soares (2007) como um dos fatores mais relevantes para o enfrentamento da violência. Estudos apontam que maior acesso à renda, educação e ambientes com maior vínculo associativo afasta os indivíduos da probabilidade da violência letal (Soares, 2007). As condições de vida mais precárias vivenciadas por grande parte da população negra expõem parte significativa desse grupo à maior incidência da violência - especialmente a juventude negra - como vítimas ou perpetradores.

Diferentes políticas públicas são necessárias em diferentes épocas e para diferentes grupos da população. Os avanços precisam ser mantidos e aperfeiçoados como bem coletivo, assim como a produção do conhecimento sobre os impactos da medida. Amplia-se, cada vez mais, o campo de estudos iniciado com a introdução das Cotas étnico-raciais e sociais, apontando como necessidade a realização de estudos longitudinais que levem em consideração as influências de medidas de inclusão social de jovens tanto no âmbito das expectativas de vida e de futuro individuais quanto no âmbito das transformações culturais e históricas nacionais.

\section{Referências}

Alisson, E. (2014, 7 de fevereiro). Políticas de inclusão atreladas apenas ao vestibular são insuficientes, aponta pesquisador. Agência FAPESP. Recuperado: 12 de fevereiro, 2014, de http:// agencia.fapesp.br/18592.

Andrade, E. D. C. (2010). Higher education: free tuition vs. quotas vs. targeted vouchers. Estudos Econômicos, 40(1), 43-66.

Athayde, F. L. O. (2010). Ações Afirmativas, Cotas e a Inserção de Acadêmicos Indígenas na Universidade Estadual de Mato Grosso do Sul (UEMS). Dissertação de Mestrado em Educação. Programa de Pós-Graduação em Educação. Universidade Católica Dom Bosco, Campo Grande, MS.

Bardin, L.(1977). Análise de Conteúdo. Lisboa: Edições 70.

Bolonha, C.\& De Teffé, C. (2012). Cotas Universitárias no Brasil: Uma Análise Sobre o Comportamento Institucional. Revista da Faculdade de Direito da UFPR, 55.

Cardoso, C. B. (2008). Efeitos da política de cotas na Universidade de Brasilia: uma análise do rendimento e da evasão. Dissertação de Mestrado, Universidade de Brasília (UnB), Brasília, DF. Studies, 44(02), 235-260.

Cicalo, A. (2012). Nerds and Barbarians: Race and Class Encounters through Affirmative Action in a Brazilian University. Journal of Latin American

Cicalo, A. (2013). Race and Affirmative Action: The implementation of quotas for" black" students in a Brazilian University. Antípoda: Revista de Antropología y Arqueología, 16, 113-134.

Daflon, V. T., Feres Júnior, J., \&Campos, L. (2013). Ações afirmativas raciais no ensino superior público brasileiro: um panorama analítico. Cadernos de Pesquisa, 43(148), 302-327.

Durham, E. R. (2005). Inequality in education and quotas for black students in universities. Novos Estudos-CEBRAP, 1(SE).

Ferreira, N. S. A.(2002). As pesquisas denominadas "estado da arte". Educação \& Sociedade, 23(79), 257-272.

Francis, A. M. \& Tannuri-Pianto, M. (2012a). The redistributive equity of affirmative action: Exploring the role of race, socioeconomic status, and gender in college admissions. Economics of Education Review, 31(1), 45-55.

Francis, A. M . \& Tannuri-Pianto, M. (2012b). Using Brazil's racial continuum to examine the short-term effects of affirmative action in higher education. Journal of Human Resources, 47(3), 754-784.

Garlet, M., Guimarães, G., \& Bellini, M. I. B. (2010). Cotas para estudantes indígenas: inclusão universitária ou exclusão escolar? Educação, 33(1), 65-74, jan./abr.

Gil, A. C. (2002). Como elaborar projetos de pesquisa (4a ed.). São Paulo: Atlas.

Golash-Boza, T. (2011). Paying Attention to Whiteness and Class. Du 
Guarnieri, F. V. (2008). Cotas universitárias: perspectivas de estudantes em situação de vestibular. Dissertação de Mestrado, Programa de Pós-Graduação em Psicologia, Universidade de São Paulo, Ribeirão Preto, SP.

Guarnieri, F. V. \& Melo-Silva, L. L. (2010). Perspectivas de estudantes em situação de vestibular sobre as cotas universitárias. Psicologia e Sociedade, 22(3), 486-498.

Guimarães, A. S. (2010).Entrance into Prestigious Universities and the Performance of Groups That Have Been Discriminated Against on the Vestibular. Growing Gaps: Educational Inequality around the World, 42, 59.

Guimarães, A. S., Costa, L. C., \& Kleinke, M. S. (2009). Bônus e cotas, comparando politicas de inclusão racial: Unicamp e UFBA. Artigo não publicado apresentado no Congresso LASA. Rio de Janeiro: LASA.

Instituto de Pesquisa Aplicada [IPEA] (2011). Políticas Sociais: acompanhamento e Análise, 19.

Lei $n^{\circ}$ 11.129, de 30 de junho de 2005 (2005, 30 de junho). Institui o Programa Nacional de Inclusão de Jovens - ProJovem; cria o Conselho Nacional da Juventude - CNJ e a Secretaria Nacional de Juventude; altera as Leis nos 10.683, de 28 de maio de 2003, e 10.429, de 24 de abril de 2002; e dá outras providências. Brasília, DF. Recuperado: 12 abr.2014. Disponível: http://www.planalto.gov. br/ccivil_03/_ato2004-2006/2005/lei//11129.htm

Lei $n^{\circ}$ 12.711, de 29 de agosto de 2012 (2012, 29 de agosto). Dispõe sobre o ingresso nas universidades federais e nas instituições federais de ensino técnico de nível médio e dá outras providências. Brasília, DF. Recuperado: 10 mar. 2013. Disponível: http://www. planalto.gov.br/ccivil_03/_ato2011-2014/2012/lei/l12711.htm

Lourenço, A. (2016). FAU-USP adere ao Sisu e suspende prova de habilidade específica para 2017. Portal do Guia do Estudante. Recuperado: 02 nov. 2016. Disponível: http://guiadoestudante. abril.com.br/universidades/fau-usp-adere-ao-sisu-e-suspendeprova-de-habilidade-especifica-para-2017/

Minto, L. W. (2013). Ensino Médio e Ensino Superior em São Paulo: Notas críticas sobre o PIMESP. Educação em Revista, Marília, v. 14, n. 2, p. 53-68, Jul.-Dez.

Moreno, A. C. (2015). Pelo Sisu, USP terá 225 vagas em cota para pretos, pardos e indígenas: Unidades que aderiram à cota racial falam em democratizar a universidade. Portal G1. Recuperado: 14 jun.2016. Disponível: http://g1.globo.com/educacao/ noticia/2015/07/pelo-sisu-usp-tera-225-vagas-em-cota-parapretos-pardos-e-indigenas.html.

Mayorga, C. \& Souza, L.M. (2012). Ação Afirmativa na Universidade:
Menin, M. S. D. S., Shimizu, A. D. M., Silva, D. J. D., Cioldi, F. L., \& Buschini, F. (2008). University students' representations of quota students: a confrontation of values. Educação e Pesquisa, 34(2), 255-272.

Pena, S. D. \& Bortolini, M. C. (2004). Pode a genética definir quem deve se beneficiar das cotas universitárias e demais ações afirmativas? Estudos Avançados, 18(50), 31-50.

Penha-Lopes, V. (2013). Affirmative Action and Racial Identity in Brazil: A Study of the First Quota Graduates at the State University of Rio de Janeiro. Em R. E. Hall (Org.), The Melanin Millennium: Skin Color as 21st Century International Discourse (vol.1, pp., 325-342). Ed. Springer Science, Business Media Dordrecht. DOI: 10.1007/978-94-007-4608-4_21 (online).

Pimentel, F. \& Santos Pereira, F. (2004). A Responsabilidade das Instituições de Ensino Superior Públicas com Relação à Exclusão Social: Uma Reflexão sobre a Reserva de Cotas para a Matrícula de Indivíduos Afrodescendentes. Revista de Ciências da Administração, 6(11), 1.

Santos, S. A. (2006). Who is black in Brazil? A timely or a false question in Brazilian race relations in the era of affirmative action? Latin American Perspectives, 33(4), 30-48.

Santos, J. T. \& Queiroz, D. M. (2010). Affirmative action and higher education in Brazil. International Encyclopedia of Education, 1, 760-766

Santos, J. T. (2012). Cotas nas universidades: análises dos processos de decisão. Salvador: Centro de Estudos Afro-orientais.

Schulze, C. J. (2012). Igualdade, discriminação positiva, cotas e ADPF 186. Revista Jus Navigandi,17(3228). Recuperado: 16 ago. 2013. Disponível: https://jus.com.br/artigos/21671.

Schwartzman, L. F. (2009). Seeing like citizens: unofficial understandings of official racial categories in a Brazilian university. Journal of Latin American Studies, 41(2), 221-250.

Silva, P. B. \& Silva, P. (2012). Representação Social de Estudantes Universitários sobre Cotas na Universidade. Fractal: Revista de Psicologia, 24(3), 525-542.

Soares, S. (2007). Educação: um escudo contra o homicídio? Brasília: Instituto de Pesquisa econômica aplicada. Recuperado: 20 fev.2014. Disponível: www.ipea.gov.br/sites/000/2/publicacoes/ tds/td_1298.pdf.

Tessler, L. R. (2006, 16 de agosto). Cota não é sinônimo de ação afirmativa. Opinião. Jornal Folha de São Paulo. Recuperado: 08 abr. 2013. Disponível: http://www1.folha.uol.com.br/fsp/ opiniao/ fz1608200608.htm. 
Universidade Estadual Paulista [UNESP] (2015). Sistema de Reserva de Vagas para Educação Básica Pública (SRVEBP).Portal da Universidade Estadual Paulista "Júlio Mesquita Filho", disponível em: http://www.unesp.br/portal\#!/proex/permanencia-studantil/ historico/inclusao-srvebp/

Vasconcelos, S. D. \& Silva, E. D. (2005). Acesso à universidade pública através de cotas: uma reflexão a partir da percepção dos alunos de um pré-vestibular inclusivo. Ensaio: Avaliação de Políticas Públicas Educacionais, 13(49), 453-68.

Waiselfisz, J. J. (2013). Mapa da Violência 2013: Homicídios e Juventude no Brasil. Brasília, DF, 2013.
Weller, W. \& Silveira, M. (2008). Ações afirmativas no sistema educacional: trajetórias de jovens negras da Universidade de Brasília. Revista Estudos Feministas, 16(3), 931-948.

Winther, J. M. \& Golgher, A. B. (2010). Uma investigação sobre a aplicação de bônus adicional como política de ação afirmativa na Universidade Federal de Minas Gerais (UFMG). Revista Brasileira de Estudos Populacionais, 27(2), 333-359.

\section{Sobre as autoras}

Fernanda Vieira Guarnieri (fervigua@yahoo.com.br)

Prefeitura Municipal de Orlândia (SP). Psicóloga, Mestre em Ciências na Área de Psicologia pela FFCLRP-USP.

Lucy Leal Melo-Silva (lucileal@ffclrp.usp.br)

Faculdade de Filosofia, Ciências e Letras (FFCLRP), Universidade de São Paulo (USP). Psicóloga, livre-docente pela FFCLRP-USP.

Notas : 1. As Arguições de Descumprimento de Preceito Fundamental (ADPFs) são recursos do poder judiciário realizadas sempre que há questionamentos sobre qualquer tipo de política ou causa que de alguma forma suscite dúvidas quanto a preceitos fundamentais presentes na Constituição Federal vigente. 2. O Conselho Nacional de Juventude (CONJUVE) foi criado em 2005 pela Lei 11.129, que também instituiu a Secretaria Nacional de Juventude e o Programa Nacional de Inclusão de Jovens (Projovem). As atribuições do Conselho consistem na formulação, proposição de diretrizes para políticas públicas e estudos sobre a juventude. 
